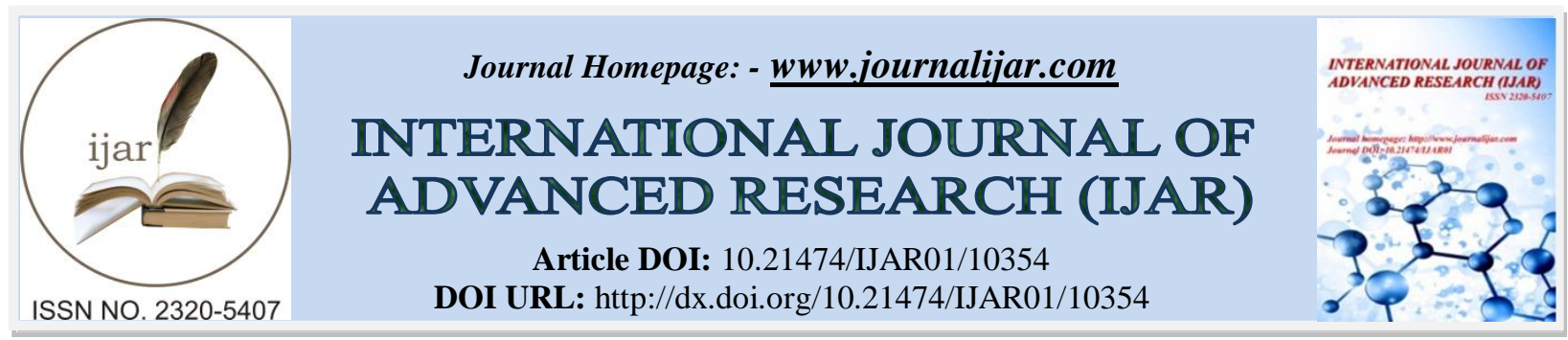

RESEARCH ARTICLE

\title{
COMPARATIVE STUDY OF DEMIRJIAN AND CAMERIERE METHODS FOR DENTAL AGE ESTIMATION OF CHILDREN AGED 5-13 YEAR IN DELHI-NCR REGION
}

\footnotetext{
Dr. Vikash Ranjan ${ }^{1}$, Dr. Praneeta Priya ${ }^{2}$, Dr. V. Naveen Shankar ${ }^{3}$ and Dr. Soumendu Bikash Maiti ${ }^{4}$

1. Associate Professor, Department Of Oral Medicine And Radiology, Divya Jyoti Collge Of Dental Sciences And Research, Modinagar.

2. Postgraduate Student, Department Of Oral Medicine And Radiology, Divya Jyoti Collge Of Dental Sciences And Research, Modinagar.

3. Professor, Department Of Oral Medicine And Radiology, Divya Jyoti Collge Of Dental Sciences And Research, Modinagar.

4. Senior Lecture, Department Of Oral Medicine And Radiology, Divya Jyoti Collge Of Dental Sciences And Research, Modinagar.
}

\section{Manuscript Info}

(..........................

Manuscript History

Received: 27 November 2019

Final Accepted: 30 December 2019

Published: January 2020

Key words:-

Demirjian, Cameriere, Estimation,

Panoramic, Mandible
Abstract

Aim: The purpose of this study was to comparative study of Demirjian and Cameriere methods for dental age estimation of children aged 513 year in DELHI-NCR region.

Settings and Design: The design of this study was a retrospective study of panoramic radiographs. Randomly 40 selected digital panoramic radiographs of children, both males and females in mixed dentition period (5-13 years), taken as part of diagnostic procedure, showing all seven left permanent teeth.

Results: In comparison with the present study done on 5 - 13 year old children both DM and CM can be used for assessing CA. When comparing the estimated DA with the CA, DM overestimated the age and $\mathrm{CM}$ underestimated. But the value showed $\mathrm{CM}$ to be more accurate than DM as CM underestimated by 0.8667 years where as DM overestimated the age by 1.767 .

Conclusions: Cameriere method of dental age estimation is more accurate than Demirjian method for estimating the age among dental age estimation of children aged 5-13 year in DELHI-NCR region.

Copy Right, IJAR, 2020,. All rights reserved.

\section{Introduction:-}

Growth and development of a child has long fascinated poets, parents and paediatricians, but the diversity in its expression has left a lot unsatisfied. The accurate age estimation has been of considerable importance in the field of Forensic Odontology as well as in Paediatrics research.Teeth formation is widely used to assess maturity and predict age. This information aids in diagnosis and treatment planning in clinical as well as in forensic dentistry. Dental age estimation is based on morphological, histological, biochemical and radiological assessment of teeth. Radiographic age estimation using teeth rely on developmental stages of teeth especially in children .This makes utilization of radiographic methods for age estimation a practical method especially in living individuals as it is a simple, nondestructive and a reliable method. Moreover, it can also be used in dead persons as well as in skeletal remains. ${ }^{1,2}$

Corresponding Author:- Dr. Vikash Ranjan

Address:- Associate Professor, Department Of Oral Medicine And Radiology, Divya Jyoti Collge Of

Dental Sciences And Research, Modinagar. 
Age estimation is also proving valuable information when birth data is lacking or doubted in the management of immigration to help determine physiological age. The scientific basis of age estimation is the genetic control of ontogenesis, which delimits the temporal variation of developmental stages. According to the suggestions produced by the Study Group on Forensic Age Diagnostics, a forensic age estimate of a living person for the purpose of criminal prosecution should consist of a physical examination that also records anthropometric data, any agerelevant developmental disorders and signs of sexual maturation; an X-ray examination of the left hand; and a dental examination that records dentition status and evaluates an orthopantomograph.

\section{Material And Methods:-}

Total 40 panoramic radiographs were used to see the calcification stages of the seven permanent left mandibular teeth .Comparison of teeth was done with Dental Age Estimation chart (DAEcc) to identify the correct stage, assign the corresponding score, and finally calculate the total score for subsequent dental age assessment that is, estimated age data were recorded, analysed, and sent for statistical analysis for results. The soft copies of the radiographs of selected subjects were retrieved from the computer attached to the digital orthopantomogram machine (Kodak8000). Digital panoramic radiographs (OPGs) of all children were assessed the for maturation status on the basis of calcification of the permanent teeth.

\section{Demirjian Method:-}

In which the mandibular left side, from central incisor to the second molar, is considered (7 teeth method) it is based on scoring system in which each tooth will have a rating which is converted into score using the table given by Demirjian for both boys and girls. The scores for seven for all seven teeth are added together to give the maturity score. The maturity score may be plotted on the centile charts (boys and girls as appropriate) to know the dental age of the child. The maturity score of 35 for a boy aged 5.0 years lies just above the 90 th centile. The maturity score may be converted directly into the dental age either by reading off on the horizontal scale the age at which the 50th centile attains the maturity score value or by using table which has been constructed by this means

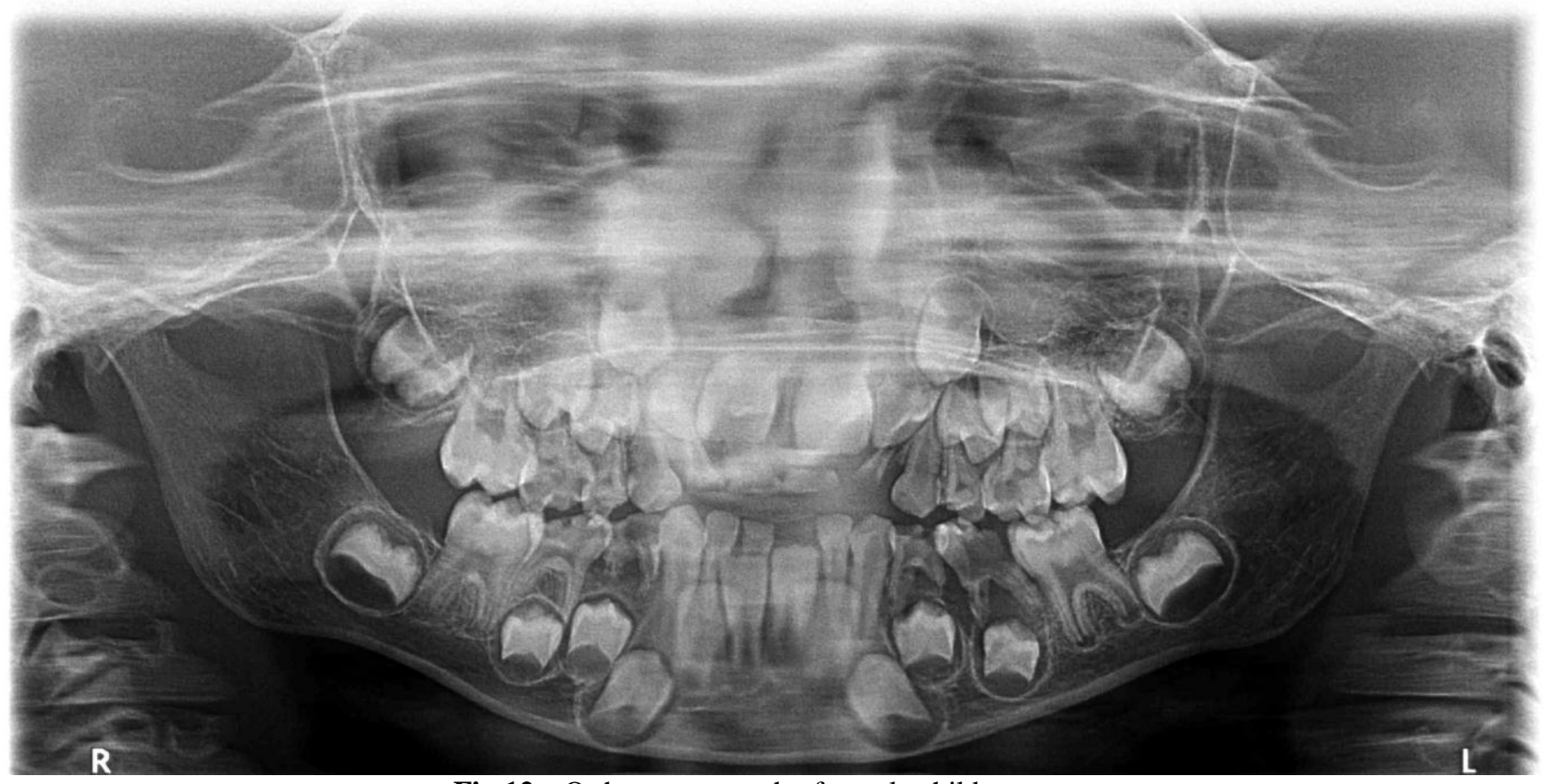

Fig 12:- Orthopantograpgh of a male child. 
\% Teeth (Mandibular Left Side)

\begin{tabular}{|c|c|c|c|c|c|c|c|c|c|}
\hline \multirow[b]{2}{*}{ Tooth } & \multicolumn{9}{|c|}{ Boys } \\
\hline & 0 & A & B & C & D & $\mathrm{E}$ & $\mathbf{F}$ & G & $\mathrm{H}$ \\
\hline $\mathrm{M}_{2}$ & 0.0 & 2.1 & 3.5 & 5.9 & 10.1 & 12.5 & 13.2 & 13.6 & 15.4 \\
\hline $\mathrm{M}_{1}$ & & & & 0.0 & 8.0 & 9.6 & 12.3 & 17.0 & 19.3 \\
\hline $\mathrm{PM}_{2}$ & 0.0 & 1.7 & 3.1 & 5.4 & 9.7 & 12.0 & 12.8 & 13.2 & 14.4 \\
\hline $\mathrm{PM}_{1}$ & & & 0.0 & 3.4 & 7.0 & 11.0 & 12.3 & 12.7 & 13.5 \\
\hline C & & & & 0.0 & 3.5 & 7.9 & 10.0 & 11.0 & 11.9 \\
\hline$I_{2}$ & & & & 0.0 & 3.2 & 5.2 & 7.8 & 11.7 & 13.7 \\
\hline$I_{1}$ & & & & & 0.0 & 1.9 & 4.1 & 8.2 & 11.8 \\
\hline
\end{tabular}

Girls

\begin{tabular}{|c|c|c|c|c|c|c|c|c|c|}
\hline & Stage & & & & & & & & \\
\hline Tooth & 0 & A & B & C & D & E & F & G & H \\
\hline $\mathrm{M}_{2}$ & 0.0 & 2.7 & 3.9 & 6.9 & 11.1 & 13.5 & 14.2 & 14.5 & 15.6 \\
\hline $\mathrm{M}_{1}$ & & & & 0.0 & 4.5 & 6.2 & 9.0 & 14.0 & 16.2 \\
\hline $\mathrm{PM}_{2}$ & 0.0 & 1.8 & 3.4 & 6.5 & 10.6 & 12.7 & 13.5 & 13.8 & 14.6 \\
\hline $\mathrm{PM}_{1}$ & & & 0.0 & 3.7 & 7.5 & 11.8 & 13.1 & 13.4 & 14.1 \\
\hline C & & & & 0.0 & 3.8 & 7.3 & 10.3 & 11.6 & 12.4 \\
\hline $\mathrm{I}_{2}$ & & & & 0.0 & 3.2 & 5.6 & 8.0 & 12.2 & 14.2 \\
\hline$I_{1}$ & & & & & 0.0 & 2.4 & 5.1 & 9.3 & 12.9 \\
\hline
\end{tabular}

Fig 13:- Rating for various stages of teeth development as per Demerjian method ${ }^{4}$

\section{Cameriere's Method:-}

The orthopantomograph were taken of the patient belongs to age group of 5-13 years a taken course of diagnosis and treatment, was selected.Dental age $=9.402-0.879 \mathrm{c}+0.663 \mathrm{~N} 0-0.711 \mathrm{~s}-0.106 \mathrm{sN} 0$

For teeth with two roots, Ai, i=6, 7, the sum of the distances between the inner sides of the two open apices was evaluated. To take into account the effect of possible differences in magnification and angulation among radiographs, measurements were normalized by dividing by tooth length $(\mathrm{Li}, \mathrm{i}=1, \ldots, 7)$. Lastly, dental maturity was evaluated with the normalized measurements of the seven permanent left mandibular teeth $(x i=\mathrm{Ai} / \mathrm{Li}, \mathrm{i}=1, \ldots, 7)$, the sum of normalized open apices s $1 / 4 \times 1 \times 2 \times 3 \times 4 \times 5 ð \times 6 \times 7$, and the number ( N0) of teeth with root development complete.

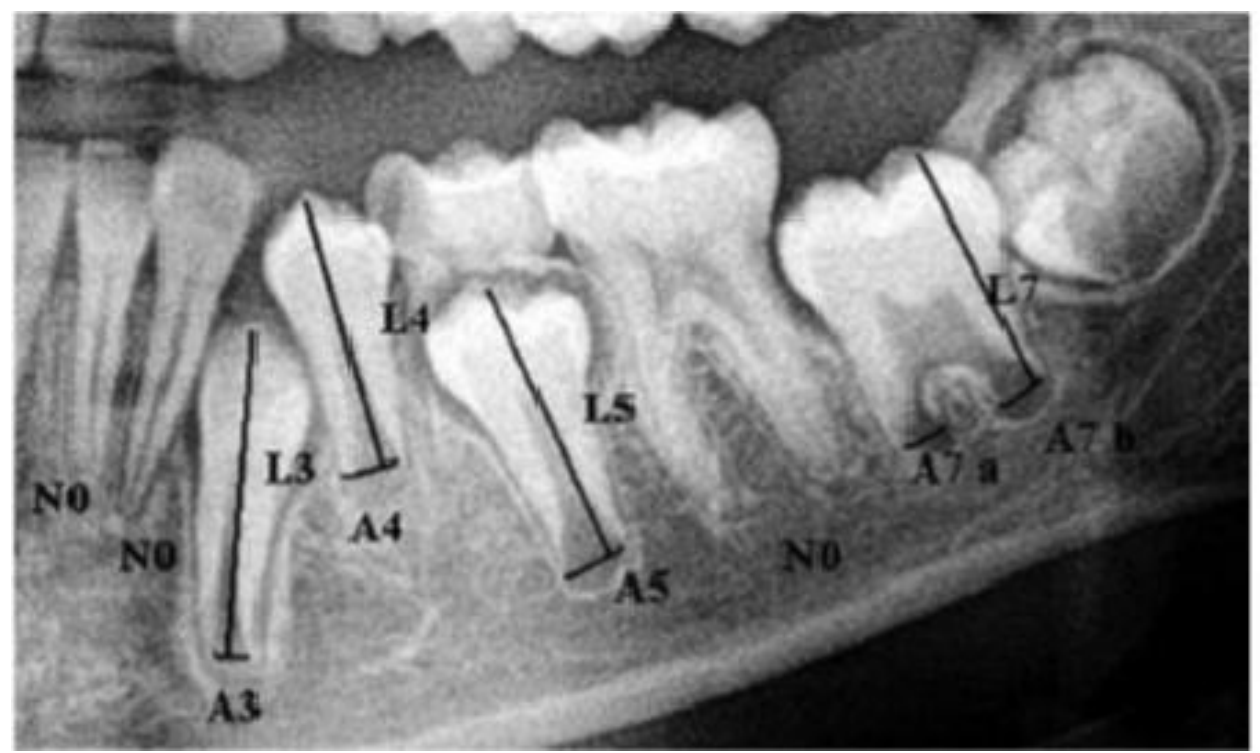

Fig 14:-Example of calculation of with and length of apices as per Cameriere's method 


\section{Results:-}

Present study conducted for determining the age of the individual and compare the determined age with accurate age by two age estimation methods Demirjian and Cameriere and compare both the methods to find out more reliable method among them. A total of 40 study samples has been collected as per inclusion and exclusion criteria from Delhi NCR region. The sample distribution across age-groups and sexes of collected sample is shown in Table 1.

Table 1:-Study sample distribution across age-groups and sexes.

\begin{tabular}{|l|l|l|l|l|l|}
\hline Age Group & Total & Male & Female & \% Male & \% Female \\
\hline Min - 5; Max -7 & 14 & 8 & 6 & 20 & 15 \\
\hline Min - 8; Max - 10 & 17 & 12 & 5 & 30 & 12.5 \\
\hline Min - 11; Max - 13 & 9 & 7 & 2 & 17.5 & 5 \\
\hline All Age Group & $\mathbf{4 0}$ & $\mathbf{2 7}$ & $\mathbf{1 3}$ & $\mathbf{6 7 . 5}$ & $\mathbf{3 2 . 5}$ \\
\hline
\end{tabular}

It can be clearly observed from the Table 1 showed that out of total 40 sample size $32.5 \%$ are female where as $67.5 \%$ are male. The total sample size has been classified in three age group based on age between 5 to 7 years, 8 to 10 years and 11 to 13 years. The age group of 5 to 7 years consists of $20 \%$ male and $15 \%$ female, the age group 8 to 10 years consists of $30 \%$ male and $12.5 \%$ female whereas the age group of 11 to 13 year consists of $17.5 \%$ male and $5 \%$ female.

The accuracy of the two methods has been compared on the basis of the error observed and presented in the terms of Root mean square error (RMSE). RMSE is calculated using the following formula,

$$
R M S E=\sqrt{\left(\frac{1}{n}\left(O_{i}-P_{i}\right)^{2}\right)}
$$

Where $O_{i}$ is the observed age or chronological age and $P_{i}$ is the predicted dental age respectively, and $n$ is the number of data points. The complete analysis has been done using MS Excel spreadsheet. Table 2 shows the RMSE observed by Demirjian and Cameriere method for all age group and sexes. For each age group and each sex, the best performing method showing least error is marked with bold and underline. It can be observed from Table 2 Cameriere method showed least error across all age of population and all sexes. Overall, the RMSE for Cameriere method has been found to be 0.8668 whereas for Demirjian Method it was 1.7667 . Figure 15 a to c shows the variation of dental age observed by Demirjian Method with respect to the chronological age of subjects. It can be clearly observed that Demirjian Method overestimate the age of subjects for both male and female. Similarly, the plot of dental age observed by Cameriere method with respect to the chronological age of subjects has been presented in Figure 16 a to c. It can be clearly observed that the Cameriere method overestimate the age of male population whereas for female it shows equal scatter on both side of equality line. Overall, the Cameriere method also overestimates the age of subject.

Table 2:- RMSE observed across age-groups and sexes.

\begin{tabular}{|l|l|l|l|l|}
\hline Age Group & \multicolumn{2}{l|}{ Demirjian Method } & \multicolumn{2}{l|}{ Cameriere method } \\
\hline & Male & Female & Male & Female \\
\hline Min - 5; Max -7 & 1.6886 & 1.6867 & $\mathbf{0 . 9 8 0 3}$ & $\mathbf{0 . 9 1 2 2}$ \\
\hline Min - 8; Max -10 & 2.0512 & 1.7861 & $\underline{\mathbf{0 . 9 0 5 3}}$ & $\underline{\mathbf{0 . 9 0 2 7}}$ \\
\hline Min - 11; Max -13 & 1.5506 & 0.922 & $\underline{\mathbf{0 . 6 1 3 4}}$ & $\underline{\mathbf{0 . 6 4 5 5}}$ \\
\hline All Age Group & 1.8271 & 1.6342 & $\mathbf{0 . 8 6 4}$ & $\mathbf{0 . 8 7 2 7}$ \\
\hline All Age for all sexes & 1.7667 & $\underline{\mathbf{0 . 8 6 6 8}}$ & \\
\hline
\end{tabular}




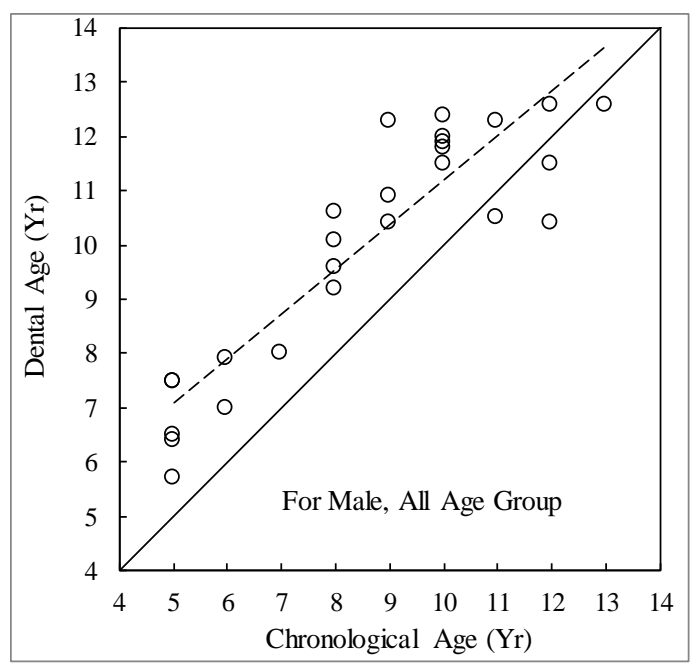

(a)

Male, All age group

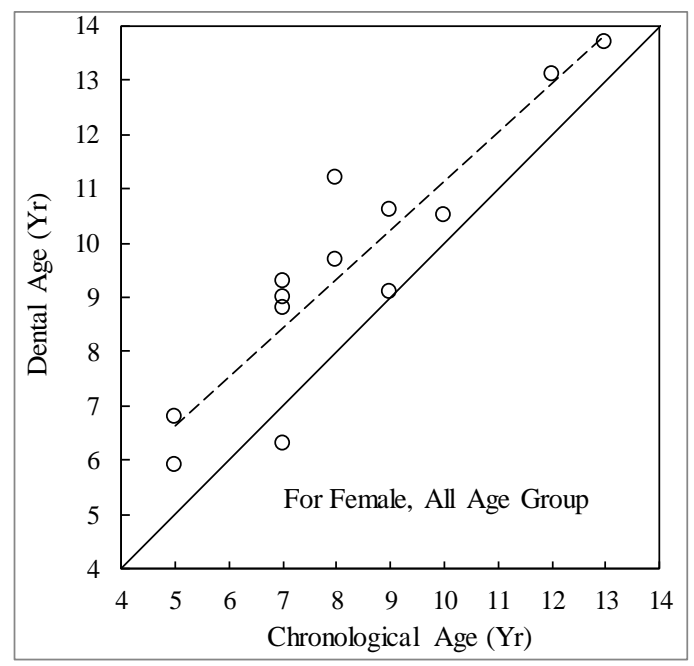

(b) Female, All age group

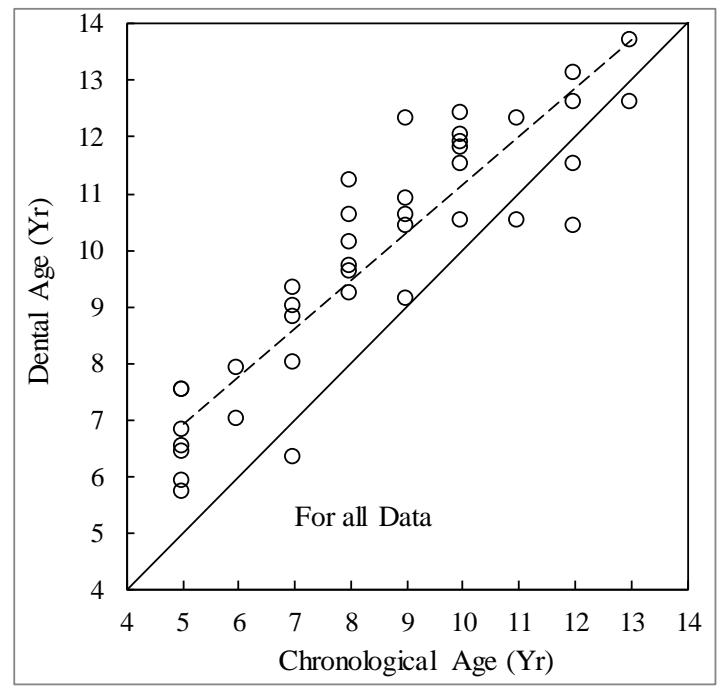

(c) All data

Fig 15:- Variation of Dental age observed by Demirjian Method with Chronological age.

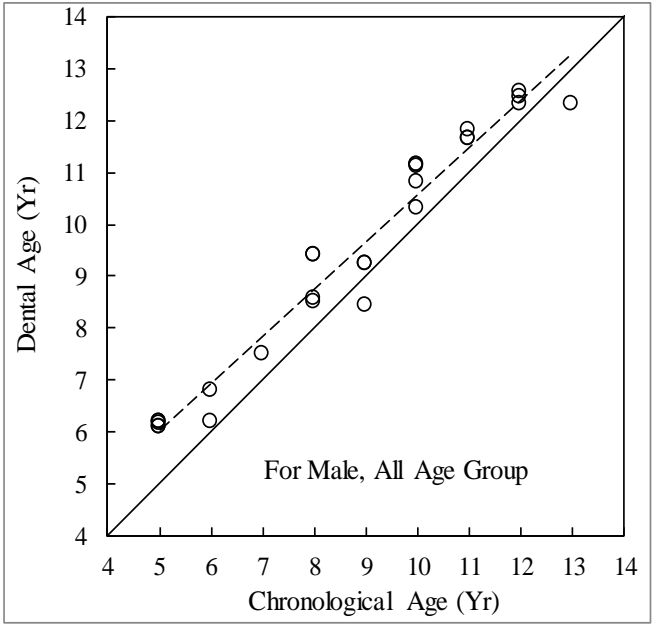

(a) Male, All age group

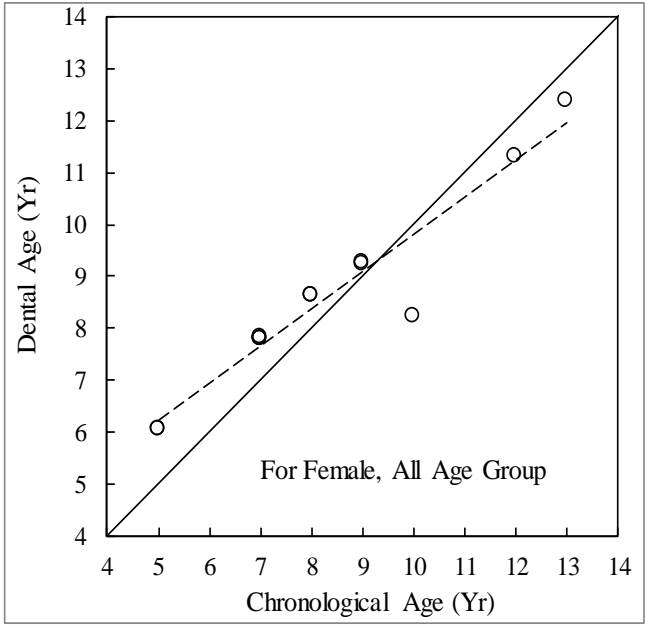

(b) Female, All age group 


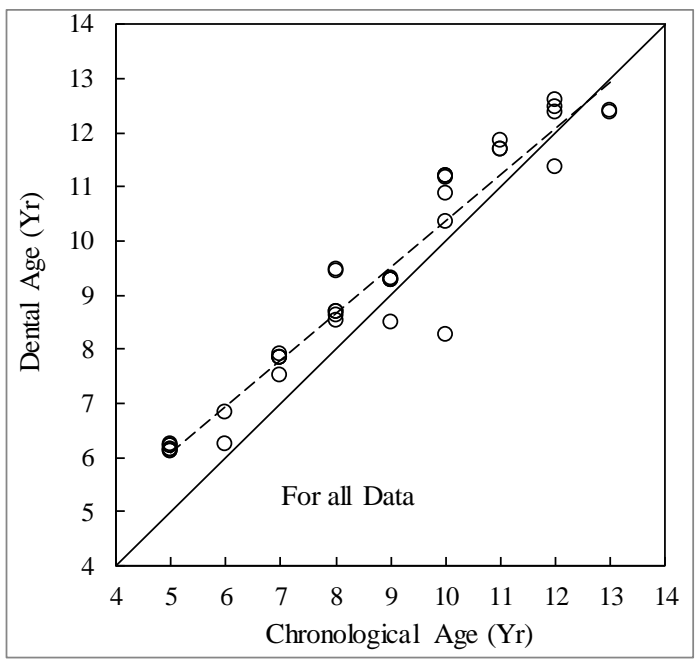

(c) All data

Fig 16:- Variation of Dental age observed by Cameriere Method with Chronological age.

The significance in the observation of subject is evaluated using two different methods. Student's T-test (Two samples assuming equal variance; Two tail distribution) and Analysis of Variance (ANOVA: Single factor) has been done on the data for each age group and sexes. MS Excel spread sheet has been used for the analysis. A null hypothesis is assumed that there is no statically significant difference in the mean of observed data for each method. For the Student's T-test, the $\mathrm{p}$ value or probability value of rejection of hypothesis is set at $5 \%$ or 0.05 . For the ANOVA test, the $\mathrm{F}$ value is estimated for each data set. If $\mathrm{F}$ value is less than critical $\mathrm{F}$ value then the Null hypothesis is accepted or vice versa. Table 3 shows the gender wise and age wise $\mathrm{p}$ value and its inference evaluated by Student's t-test as statistically significant difference in mean value of data sets as observed by chronological age and dental age by Demirjian and Cameriere method. Table 4 shows the Estimated F value, Critical F-value and its inference as statistically significant difference in mean value of data set observed as evaluated by ANOVA test.

It can be clearly observed from Table 3 and 4 that there is significant difference in mean age of male subject of all age group as observed from Demirjian method whereas for female subjects, there is no significant difference is observed. The Cameriere method shows that for both male and female subjects, there is no significant difference in the mean age of subjects. Over all there is a significant difference in mean age of overall population estimated using Demirjian Method which is also reflected in higher RMSE. For Cameriere Method, there is no significant difference in mean age estimated for overall population which is also reflected in lower RMSE.

Table 3:- Gender wise and age wise differences between the chronological age and estimated age for the two methods using Student's t-Test.

\begin{tabular}{|c|c|c|c|c|c|c|c|}
\hline \multirow{3}{*}{$\begin{array}{l}\text { Age Group } \\
\text { Min - 5 Year } \\
\text { Max - } 7 \text { Year }\end{array}$} & \multirow[t]{2}{*}{ Parameters } & \multicolumn{2}{|c|}{$\begin{array}{l}\text { Chronological Age } \\
\text { (Yr) }\end{array}$} & \multicolumn{2}{|c|}{$\begin{array}{l}\text { Demirjian's Method Age } \\
\text { (Yr) }\end{array}$} & \multicolumn{2}{|c|}{$\begin{array}{l}\text { Cameriere's Method Age } \\
\text { (Yr) }\end{array}$} \\
\hline & & Male & Female & Male & Female & Male & Female \\
\hline & Mean & 5.500 & 6.333 & 7.063 & \begin{tabular}{|l}
7.683 \\
\end{tabular} & 6.414 & 7.237 \\
\hline & Std. Dev & 0.756 & 1.033 & 0.809 & 1.514 & 0.492 & 0.896 \\
\hline & Variance & 0.571 & 1.067 & 0.654 & 2.294 & 0.243 & 0.803 \\
\hline & Count & 8 & 6 & 8 & 6 & 8 & 6 \\
\hline & $\mathrm{T}$ value & & & 3.992 & 1.804 & 2.865 & 1.618 \\
\hline & $\mathrm{P}$-value & & & 0.00134 & 0.1014 & 0.0125 & 0.1367 \\
\hline & Inference & & & $\mathbf{S}$ & NS & $\mathbf{S}$ & NS \\
\hline \multirow{6}{*}{$\begin{array}{l}\text { Min }-8 \text { Year } \\
\text { Max }-10 \text { Year }\end{array}$} & Mean & 9.083 & 8.800 & 11.058 & 10.220 & 9.791 & 8.820 \\
\hline & Std. Dev & 0.900 & 0.837 & 1.081 & 0.823 & 1.076 & 0.439 \\
\hline & Variance & 0.811 & 0.700 & 1.168 & 0.677 & 1.157 & 0.193 \\
\hline & Count & 12 & 5 & 12 & 5 & 12 & 5 \\
\hline & $\mathrm{T}$ value & & & 4.864 & 2.706 & 1.747 & 0.047 \\
\hline & $\mathrm{P}$-value & & & 0.00007 & 0.0268 & 0.0946 & 0.963 \\
\hline
\end{tabular}




\begin{tabular}{|c|c|c|c|c|c|c|c|}
\hline & Inference & & & $\mathbf{S}$ & $\mathbf{S}$ & NS & NS \\
\hline \multirow{7}{*}{$\begin{array}{l}\text { Min - } 11 \text { Year } \\
\text { Max - } 13 \text { Year }\end{array}$} & Mean & 11.72 & 12.500 & 12.043 & 13.400 & 12.117 & 11.855 \\
\hline & Std. Dev & 0.756 & 0.707 & 1.391 & 0.424 & 0.387 & 0.742 \\
\hline & Variance & 0.571 & 0.500 & 1.936 & 0.180 & 0.150 & 0.551 \\
\hline & Count & 7 & 2 & 7 & 2 & 7 & 2 \\
\hline & $\mathrm{T}$ value & & & 0.549 & 1.543 & 1.255 & 0.890 \\
\hline & P-value & & & 0.5931 & 0.2627 & 0.233 & 0.468 \\
\hline & Inference & & & NS & NS & NS & NS \\
\hline \multirow[t]{7}{*}{ All Age Group } & Mean & 8.704 & 8.231 & 10.130 & 9.538 & 9.393 & 8.556 \\
\hline & Std. Dev & 2.509 & 2.386 & 2.323 & 2.366 & 2.322 & 1.777 \\
\hline & Variance & 6.293 & 5.692 & 5.395 & 5.596 & 5.392 & 3.158 \\
\hline & Count & 27 & 13 & 27 & 13 & 27 & 13 \\
\hline & T value & & & 2.167 & 1.403 & 1.048 & 0.394 \\
\hline & P-value & & & 0.0348 & 0.1733 & 0.2993 & 0.6968 \\
\hline & Inference & & & $\mathbf{S}$ & NS & NS & NS \\
\hline \multirow{7}{*}{$\begin{array}{l}\text { Complete } \\
\text { Population }\end{array}$} & Mean & \multicolumn{2}{|l|}{8.550} & \multicolumn{2}{|l|}{9.938} & \multicolumn{2}{|l|}{9.121} \\
\hline & Std. Dev & \multicolumn{2}{|l|}{2.449} & \multicolumn{2}{|l|}{2.323} & \multicolumn{2}{|l|}{2.173} \\
\hline & Variance & \multicolumn{2}{|l|}{5.997} & \multicolumn{2}{|l|}{5.397} & \multicolumn{2}{|l|}{4.724} \\
\hline & Count & \multicolumn{2}{|l|}{40} & \multicolumn{2}{|l|}{40} & \multicolumn{2}{|l|}{40} \\
\hline & $\mathrm{T}$ value & & & \multicolumn{2}{|l|}{2.600} & \multicolumn{2}{|l|}{1.103} \\
\hline & P-value & & & \multicolumn{2}{|l|}{0.0112} & \multicolumn{2}{|l|}{0.2732} \\
\hline & Inference & & & \multicolumn{2}{|l|}{$\mathbf{S}$} & \multicolumn{2}{|l|}{ NS } \\
\hline
\end{tabular}

$* \mathrm{~S}=$ Significant $; \mathrm{NS}=$ Not Significant

Table 4:- Gender wise and age wise differences between the chronological age and estimated age for the two methods using ANOVA test.

\begin{tabular}{|c|c|c|c|c|c|c|c|}
\hline \multirow{9}{*}{$\begin{array}{l}\text { Age Group } \\
\text { Min - 5 Year } \\
\text { Max - } 7 \text { Year }\end{array}$} & \multirow{3}{*}{$\begin{array}{l}\text { Parameters } \\
\text { Mean }\end{array}$} & \multicolumn{2}{|c|}{$\begin{array}{l}\text { Chronological Age } \\
\text { (Yr) }\end{array}$} & \multicolumn{2}{|c|}{$\begin{array}{l}\text { Demirjian's Method Age } \\
\text { (Yr) }\end{array}$} & \multicolumn{2}{|c|}{$\begin{array}{l}\text { Cameriere's Method Age } \\
\text { (Yr) }\end{array}$} \\
\hline & & Male & Female & Male & Female & Male & Female \\
\hline & & 5.500 & 6.333 & 7.063 & 7.683 & 6.414 & 7.237 \\
\hline & Std. Dev & 0.756 & 1.033 & 0.809 & 1.514 & 0.492 & 0.896 \\
\hline & Variance & 0.571 & 1.067 & 0.654 & 2.294 & 0.243 & 0.803 \\
\hline & Count & 8 & 6 & 8 & 6 & 8 & 6 \\
\hline & F value & & & 15.937 & 3.2541 & 8.2061 & 2.6183 \\
\hline & F-critical & & & 4.600 & 4.765 & 4.6001 & 4.91646 \\
\hline & Inference & & & $\mathbf{S}$ & $\mathbf{S}$ & $\mathbf{S}$ & NS \\
\hline \multirow{7}{*}{$\begin{array}{l}\text { Min }-8 \text { Year } \\
\text { Max - } 10 \text { Year }\end{array}$} & Mean & 9.083 & 8.800 & 11.058 & 10.220 & 9.791 & 8.820 \\
\hline & Std. Dev & 0.900 & 0.837 & 1.081 & 0.823 & 1.076 & 0.439 \\
\hline & Variance & 0.811 & 0.700 & 1.168 & 0.677 & 1.157 & 0.193 \\
\hline & Count & 12 & 5 & 12 & 5 & 12 & 5 \\
\hline & F value & & & 23.656 & 7.3217 & 3.0523 & 0.00224 \\
\hline & F-critical & & & 4.301 & 5.318 & 4.301 & 5.3177 \\
\hline & Inference & & & $\mathbf{S}$ & $\mathbf{S}$ & NS & NS \\
\hline \multirow{7}{*}{$\begin{array}{l}\text { Min - 11 Year } \\
\text { Max - 13 Year }\end{array}$} & Mean & 11.71 & 12.500 & 12.043 & 13.400 & 12.117 & 11.855 \\
\hline & Std. Dev & 0.756 & 0.707 & 1.391 & 0.424 & 0.387 & 0.742 \\
\hline & Variance & 0.571 & 0.500 & 1.936 & 0.180 & 0.150 & 0.551 \\
\hline & Count & 7 & 2 & 7 & 2 & 7 & 2 \\
\hline & F value & & & 0.3014 & 2.3824 & 1.5755 & 0.7914 \\
\hline & F-critical & & & 4.747 & 18.513 & 4.7472 & 18.513 \\
\hline & Inference & & & NS & NS & NS & NS \\
\hline \multirow[t]{4}{*}{ All Age Group } & Mean & 8.704 & 8.231 & 10.130 & 9.538 & 9.393 & 8.556 \\
\hline & Std. Dev & 2.509 & 2.386 & 2.323 & 2.366 & 2.322 & 1.777 \\
\hline & Variance & 6.293 & 5.692 & 5.395 & 5.596 & 5.392 & 3.158 \\
\hline & Count & 27 & 13 & 27 & 13 & 27 & 13 \\
\hline
\end{tabular}




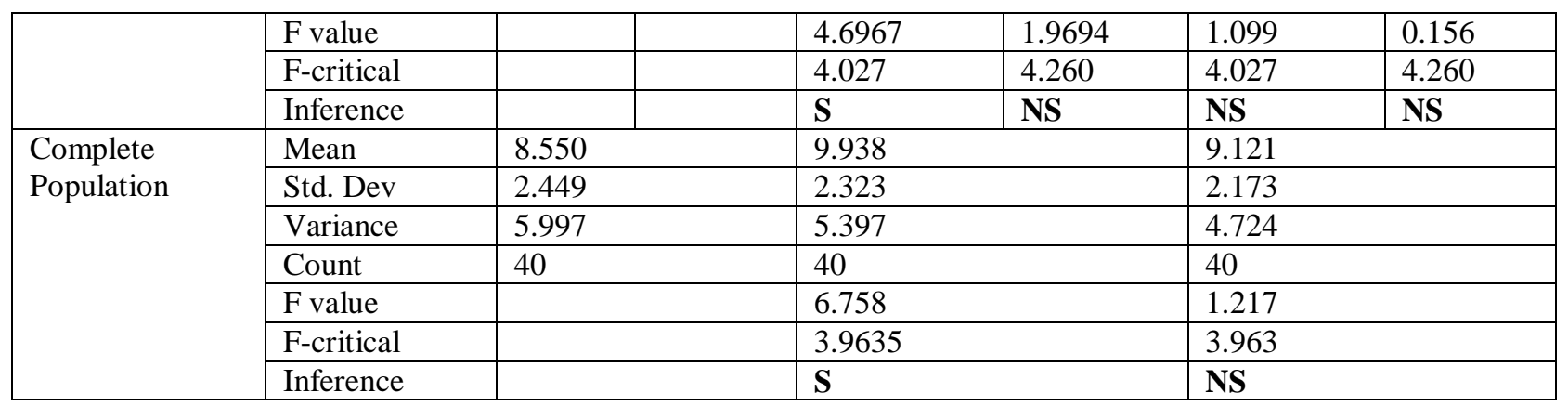

*S = Significant; NS = Not Significant

\section{Dissussion:-}

The aimed to comparative study of Demirjian and Cameriere methods for dental age estimation of children aged 513 year in DELHI-NCR region. The age range from 5-13 years remains the most critical with regard to estimating a child's dental age and consequently to determine the proper timing for orthodontic therapy. ${ }^{4,5,6}$

This age group is commonly accepted for dental age estimation in children as teeth development passes through various stages during this age group. Teeth development depends upon number of factors such as genetic factor, environmental factors, nutritional factors and geographical factors. Tooth eruption is influenced by other factors also such as space in the dental arch, extraction of deciduous predecessors tipping or impaction of teeth. During developmental stages particularly in root formation, a notable difference between sexes arises with females being advanced when compared with males. Hence the dental age estimation using developmental stages of teeth in this age group is acceptable as it is less influenced by environmental factors ${ }^{4,7,8,9,10}$

\section{Conclusion:-}

The present determined that the Demirjian shows overestimation of age and Cameriere slightly under estimation. Both the dental age estimation methods are seen to be strongly correlated with chronological age, implying the potential applicability of both the methods of dental age estimation in the Indian population; however, overestimation of the actual chronological age supports the need for population-specific standards in both the methods, for further application in forensic sciences. Although various age estimation methods do exist, the results are varied in different populations due to ethnic differences. Also, there is a lack of age estimation studies in population. Hence, further studies are needed to formulate new tables for this population.

Since our study has a small sample size, so more studies are required with large sample size.

\section{Conflict of Interest:-}

None

Source of Funding;-

None

\section{Biblography:-}

1. Rai, B., Kaur, J., Cingolani, M., Ferrante, L. and Cameriere, R., 2010. Age estimation in children by measurement of open apices in teeth: an Indian formula. International journal of legal medicine, 124(3), pp.237241

2. Hegde, R.J. and Sood, P.B., 2002. Dental maturity as an indicator of chronological age: radiographic evaluation of dental age in 6 to 13 years children of Belgaum using Demirjian methods. J Indian Soc Pedod Prev Dent, 20(4), pp.132-8.

3. Prabhakar, A.R., Panda, A.K. and Raju, O.S., 2002. Applicability of Demirjian's method of age assessment in children of Davangere. Journal of the Indian Society of Pedodontics and Preventive Dentistry, 20(2), pp.54-62.

4. Demirjian, A., Goldstein, H. and Tanner, J.M., 1973. A new system of dental age assessment. Human biology, pp.211-227.

5. Grover, S., Marya, C.M., Avinash, J. and Pruthi, N., 2012. Estimation of dental age and its comparison with chronological age: accuracy of two radiographic methods. Medicine, Science and the Law, 52(1), pp.32-3 
6. Chaudhary, R.K. and Doggalli, N., 2018. Commonly used different dental age estimation methods in children and adolescents. International Journal of Forensic Odontology, 3(2), p.50.

7. Panchbhai, A.S., 2011. Dental radiographic indicators, a key to age estimation. Dentomaxillofacial Radiology, 40(4), pp.199-212

8. RanganathanK, RoobanT, Lakshmminarayan V. Forensicodontology: A review. JForensicOdontol2008;1:4-12

9. Cameriere R, Ferrante L, Cingolani M. Variations in pulp/tooth area ratio as an indicator of age: a preliminary study. Journal of Forensic Science. 2004 Feb 19;49(2):1-3.

10. Patel, P.S., Chaudhary, A.R., Dudhia, B.B., Bhatia, P.V., Soni, N.C. and Jani, Y.V., 2015. Accuracy of two dental and one skeletal age estimation methods in 6-16 year old Gujarati children. Journal of forensic dental sciences, 7(1), p.18. 